\title{
COMPARISON OF IMPACT FORCES GENERATED BY DEBRIS FLOWS USING NUMERICAL ANALYSIS MODELS
}

\author{
DONG HO KANG ${ }^{1}$, DONG HO NAM ${ }^{1}$, SUK HO LEE ${ }^{1}$, WOO JUN YANG ${ }^{2}$, KWANG HO YOU \\ \& BYUNG SIK KIM ${ }^{1}$ \\ ${ }^{1}$ Department of Urban and Environmental Disaster Prevention Engineering, \\ Kangwon National University, Republic of Korea \\ ${ }^{2}$ SQ Engineering, Republic of Korea \\ ${ }^{3}$ Department of Civil Engineering, Republic of Korea
}

\begin{abstract}
Climate change has caused localized torrential rainfall and typhoons to occur more frequently, increasing the damage to both life and property. In particular, debris flows have caused damage not only in mountainous areas but also in urban centers. Many studies have been carried out about this, due to rising concern about debris flows. These studies applied different debris flow models and conducted analyses on the behaviors of debris flow as well as forecasting. Given this, however, the subject of the impact force of debris flows should also be taken into consideration. Thus, this study applied RAMMS and FLO-2D: two models used for the numerical analyses of debris flow to analyze impact force. In this paper, the selected study areas are Umyeonsan Mountain in Seoul and Majeoksan Mountain in Chuncheon, where damages on debris flows were caused by localized heavy rain in 2011. To identify a debris flow-triggering rainfall, we used and applied rainfall calculations carried out at different frequencies (30-year, 50-year, 100-year, 200-year). This study calculated and compared impact forces produced by the two models at any point in the study areas. Identifying impact forces based on the comparison of the two models will be useful in selecting materials and equipment appropriate when installing facilities in mountainous regions.
\end{abstract}

Keywords: RAMMS, Flo-2D, impact force.

\section{INTRODUCTION}

Debris flow is a phenomenon in which heavy rainfall causes landslides as the rain washes oil downstream, which leads to significant damage to facilities and people located on the route of the oil flow or in the sedimentation spot. The torrential and heavy rainfall brought about due to climate change in South Korea causes destruction due to debris flow. Because of exploiting the mountainous areas, debris flow is observed more frequently not only in those areas, but also in city centers, where apartments and hotels are dense, as well as in mountain villages with a large temporary population. The example cases of debris flow incidents in city centers are Mt. Woomyun (Seoul) and Mt. Majeoksan (Chuncheon), which both occurred in July 2011. The development of mountainous areas has caused an increased exposure to debris flow and, accordingly, damages to people and property. A number of studies have been carried out in relation to debris flow. For example, WSL Institute for Snow and Avalanche Research SLF developed the RAMMS model for avalanche and landslide research, studying the use of vibration sensors to monitor and detect debris flow. In this study, we applied a distributed rainfall-runoff model, S-RAT, to analyze the flood discharge, while two-dimensional numerical analysis models, Flo-2D and RAMMS, were used to compare the impact forces of debris flow. The study estimated the optimal parameters of each model using the NSI quantitative index, in order to compare the actual extent of the damage to the extent of the damage according to the model. When comparing the two models, the study used the probability of rainfall per frequency $(30,50,100$, and 200-years). The selected study areas were Remian Apartment at Mt. Woomyun in Seoul and Mt. Majeoksan in Chuncheon, which experienced actual damages from the July 2011 debris flow. To compare the two models, the 
study calculated the quantitative index for the extent of the damage and compared the impact forces.

\section{THEORETICAL BACKGROUND}

\subsection{NSI quantitative index}

The NSI quantitative index is defined in Fig. 1. It consists of the Success Index, the Error Index, and the Net Success Index, which are shown in eqns (1)-(3) [1].

$$
\begin{gathered}
\mathrm{SI}(\%)=\frac{A_{\text {coinside }}}{A_{\text {affected }}} \times 100 \\
\mathrm{EI}(\%)=\frac{A_{\text {error }}}{A_{\text {affected }}} \times 100 \\
\mathrm{NSI}(\%)=S I-E I
\end{gathered}
$$

The Error Index (EI) indicates the extent of the damage produced through the model's interpretation of the range of the mismatches between the actual extent of the damage and the extent of the damage according to the model. $A_{\text {error }}$ is shown as $A_{\text {error-A }}+A_{\text {error-B }}$ in Fig. 1. The Net Success Index (NSI) represents the accuracy of the model's analysis result, which is the sum of the Success Index (SI) minus the Error Index (EI). The study calculated the parameters of the Flo-2D and RAMMS for analysis by using this method.

\subsection{Distributed rainfall-runoff model (Spatial Runoff Assessment Tool, S-RAT)}

The S-RAT (Spatial Runoff Assessment Tool) is a distributed rainfall-runoff model, which was developed by Kim and Byung-sik et al. [2]. It divides large areas into grids of a certain size based on the GIS data. For each grid, a conceptual water balance is calculated according to the time intervals to simulate the spatial and temporal changes of the runoff in the project's watershed. Most of the distributed hydrological models rely on GIS commercial packages such as Arc-related software and IDRISH when defining the parameters. On the other hand, the S-RAT requires relatively simple input data as it extracts parameters itself. Kim, Byungsik's study "Development of a grid-based conceptual hydrological model" [2] gives details of the S-RAT.

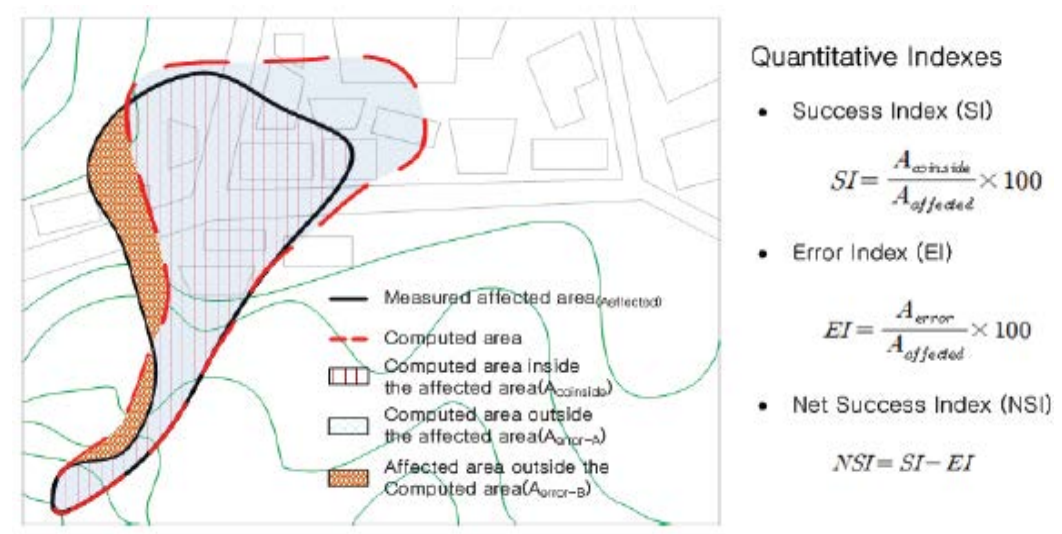

Figure 1: NSI quantitative diagram. 


\subsection{Two-dimensional numerical analysis model of debris flow: RAMMS}

RAMMS (Rapid Mass Move Simulation) is a model developed by SLF (WSL Institute for Snow and Avalanche Research), an affiliate institute of WSL (Swiss Federal Institute for Forest, Snow and Landscape Research). Dynamic modeling can be used to analyze three things - debris flow, rockfall, and avalanches - using the digital elevation model (DEM) [3]. RAMMS also has the advantage of simulating the movement of debris flow. The basic equation of the model is based on the Voellmy-Salm approach, which is shown in eqn (4).

$$
S=\mu N+(1-\mu) C-(1-\mu) \operatorname{Cexp}\left(-\frac{N}{C}\right)+\frac{\rho g U^{2}}{\delta}
$$

In the equation, $\mu$ indicates the Coulomb friction coefficient, $\mathrm{N}$ is the normal stress on the active surface, $\mathrm{C}$ is the cohesive force on the fluid material, $\rho$ is the density, and $\mathrm{U}$ is the flow rate.

\subsection{Two-dimensional numerical analysis model of debris flow: Flo-2D}

Flo-2D, developed by Flo Engineering Inc., is a two-dimensional finite difference model that can analyze non-Newtonian floods and debris flows. Flo-2D can simulate the scope and sedimentation depth of a certain amount of debris flowing from the upper stream to the downstream watershed. While it is limited in that it cannot simulate the erosion caused by flowing debris, the model is still suitable for tracking debris flow and simulating debris deposition [4]. Also, it is widely used for risk assessments of floods and debris flows. The shear stress applied to the model is calculated as the sum of the five shear stress components shown in eqn (5).

$$
\tau=\tau_{c}+\tau_{m c}+\tau_{v}+\tau_{t}+\tau_{d}
$$

In the equation above, $\tau$ is the total shear stress, $\tau_{c}$ is the cohesive yield stress, $\tau_{\mathrm{mc}}$ is the Mohr-Coulomb shear stress, $\tau_{v}$ is the viscous shear stress, $\tau_{t}$ is the turbulent shear stress, and $\tau_{d}$ is the dispersion shear stress. These components can be expressed in a two-dimensional rheological model as shown in eqn (6).

$$
\tau=\tau_{y}+\eta\left(\frac{\partial u}{\partial y}\right)+C\left(\frac{\partial u}{\partial y}\right)^{2}
$$

The integral of eqn (6) for the depth of flow is expressed as shown in eqn (7).

$$
S_{f}=S_{y}+S_{v}+S_{t d}=\frac{\tau_{y}}{\gamma_{m} h}+\frac{K \eta u}{8 \gamma_{m} h^{2}}+\frac{n^{2} u^{2}}{h^{4 / 3}}
$$

In this equation, $S_{y}$ is the yield slope, $S_{v}$ is the viscous slope, $S_{t d}$ is the turbulent-dispersion slope, $\gamma_{m}$ is the specific weight of the mixture, $n$ is the Manning coefficient, and $u$ is the velocity at the mean depth. Yield stress " $\tau_{\mathrm{y}}$ " and viscosity " $\eta$ " change with the concentration volume " $\mathrm{C}_{\mathrm{v}}$ ".

\section{APPLICATION AND RESULTS}

\subsection{Study watershed}

Mt. Woomyun in Seocho-gu, Seoul and Mt. Majeoksan in Cheonjeon-ri, Chuncheon - which experienced damage from a debris flow in July 2011 - were selected as the study watersheds. The watershed areas are $75,600 \mathrm{~m}^{2}$ and $38,300 \mathrm{~m}^{2}$, respectively. Accumulated rainfall from 
00:00 to 09:00 in Seoul was $214 \mathrm{~mm}$ for Seocho-gu, $242 \mathrm{~mm}$ for Gangnam-gu, $297 \mathrm{~mm}$ for Gwanak-gu, and $314 \mathrm{~mm}$ for Namhyeon. Accumulated rainfall from 18:00 to 23:00 in Chuncheon-si was $257 \mathrm{~mm}$ for Jicheon Elementary School, $261 \mathrm{~mm}$ for Soyang 2-gyo, and $306 \mathrm{~mm}$ for Cheonjeon-ri. In both areas, a lot of rainfall occurred. Below is an image of the pre- and post-damage in Mt. Woomyun and Mt. Majeoksan.

\subsection{Calculation of model parameters using the NSI quantitative index}

The optimal parameters were calculated using the NSI quantitative index using the actual rainfall events in July 2016. For the case of Seoul, RAMMS calculated the sediment concentration as 0.4 , the flow velocity as $8 \mathrm{~m} / \mathrm{s}$, the viscous friction coefficient as 0.2 , and the turbulent friction coefficient as 800 . For the case of Chuncheon, the model calculated the sediment concentration as 0.4 , the velocity as $8 \mathrm{~m} / \mathrm{s}$, the viscous friction coefficient as 0.1 , and the turbulent friction coefficient as 950. For the case of Seoul, Flo-2D calculated the soil specific weight as 2.5 , the roughness coefficient as 100 , the viscosity as 0.000495 , and the yield stress as 0.0385 . For the case of Chuncheon, the model calculated the soil specific weight as 2.5 , the roughness coefficient as 150 , the viscosity coefficient as 0.000635 , and the yield stress as 0.0515 . The results are shown in Tables 1 and 2 .

Fig. 4 shows the comparison of the damage range with the actual damage range and each optimal parameter applied to both models. The error rates were calculated by comparing the damage ranges of the two models (Table 3 ).

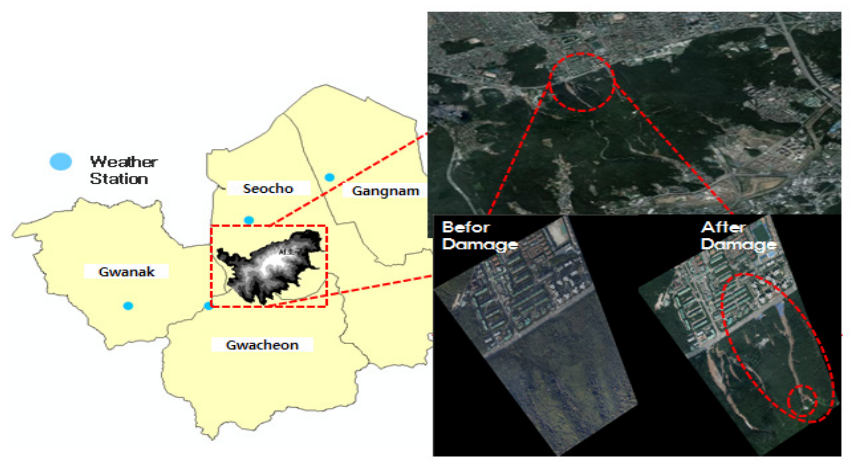

Figure 2: Damaged area in Seoul.

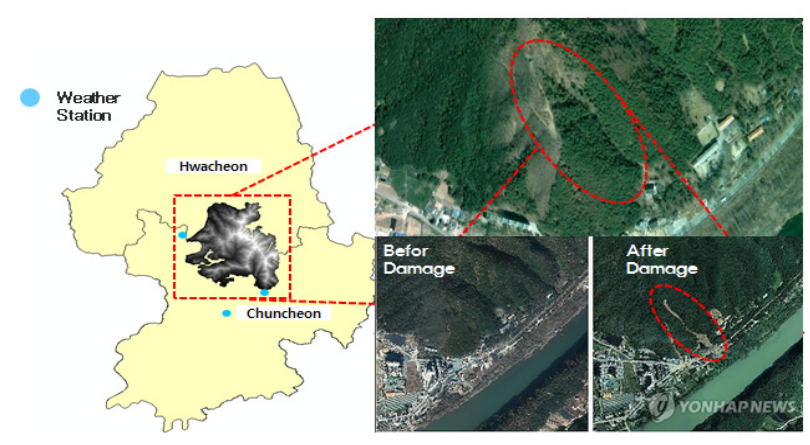

Figure 3: Damaged area in Chuncheon. 
Table 1: Optimal parameter (RAMMS).

\begin{tabular}{|c|c|c|c|c|}
\hline & $\begin{array}{c}\text { Volumetic } \\
\text { sediment } \\
\text { concentration }\end{array}$ & Velocity & Viscous friction & $\begin{array}{c}\text { Turbulent } \\
\text { friction }\end{array}$ \\
\hline Seoul & 0.4 & 8 & 0.1 & 950 \\
\hline Chuncheon & 0.4 & 8 & 0.2 & 800 \\
\hline
\end{tabular}

Table 2: Optimal parameter (Flo-2D).

\begin{tabular}{|c|c|c|c|c|}
\hline & $\begin{array}{c}\text { Sediment } \\
\text { specific } \\
\text { gravity }\end{array}$ & $\begin{array}{c}\text { Laminar flow } \\
\text { resistance }\end{array}$ & $\begin{array}{c}\text { Viscosity vs } \\
\text { Sediment } \\
\text { Concentration }\end{array}$ & $\begin{array}{c}\text { Yield vs } \\
\text { Sediment } \\
\text { Concentration }\end{array}$ \\
\hline Seoul & 2.5 & 100 & 0.000495 & 0.0385 \\
\hline Chuncheon & 2.5 & 100 & 0.000635 & 0.0515 \\
\hline
\end{tabular}

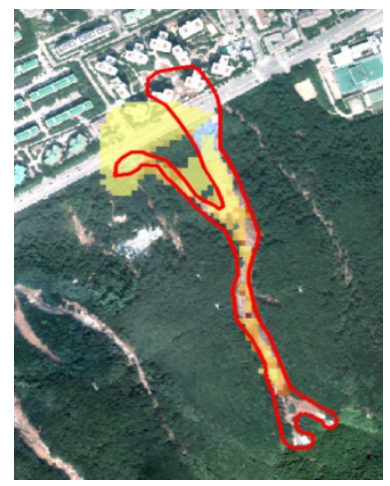

(a) RAMMS(Seoul)

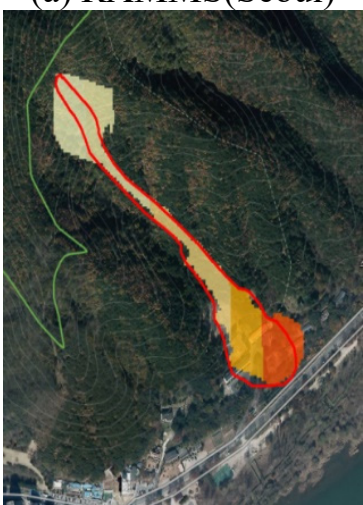

(c) RAMMS(Chuncheon)

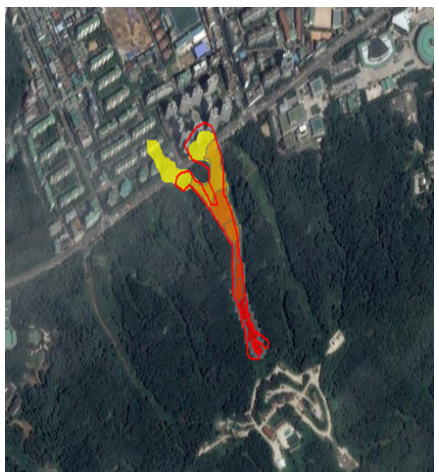

(b) Flo-2D(Seoul)

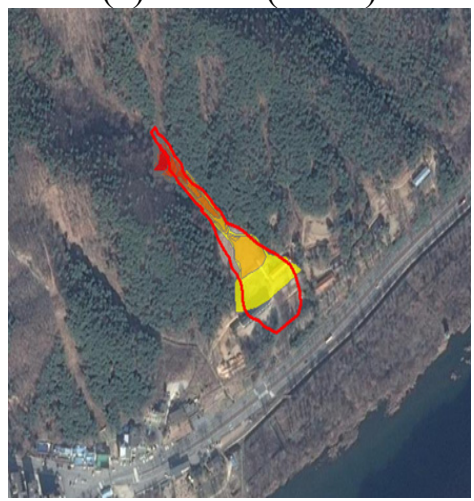

(d) Flo-2D(Chuncheon)

Figure 4: Comparison of Actual damage area and Model area after calculating optimal parameter. 
Table 3: Model application result data(Seoul).

\begin{tabular}{|c|c|c|c|c|c|}
\hline \multirow{2}{*}{ Seoul } & \multicolumn{3}{|c|}{ Damage Area $\left(m^{2}\right)$} & \multicolumn{2}{c|}{ Error rate (\%) } \\
\cline { 2 - 6 } & $\begin{array}{c}\text { Actual } \\
\text { damage area }\end{array}$ & RAMMS & Flo-2D & RAMMS & Flo-2D \\
\hline Chuncheon & 49,553 & 73,574 & 67,426 & 5.7 & 3.1 \\
\hline
\end{tabular}

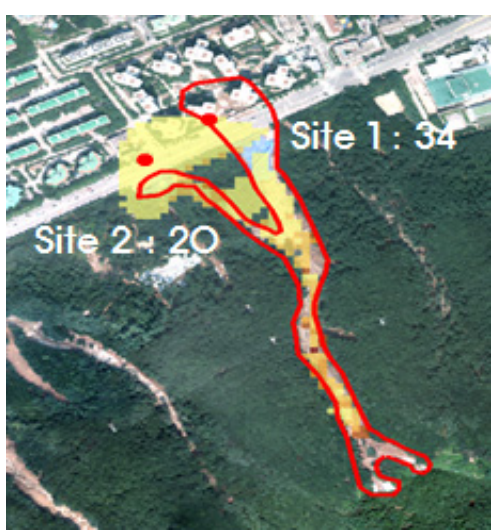

(a) 30 years

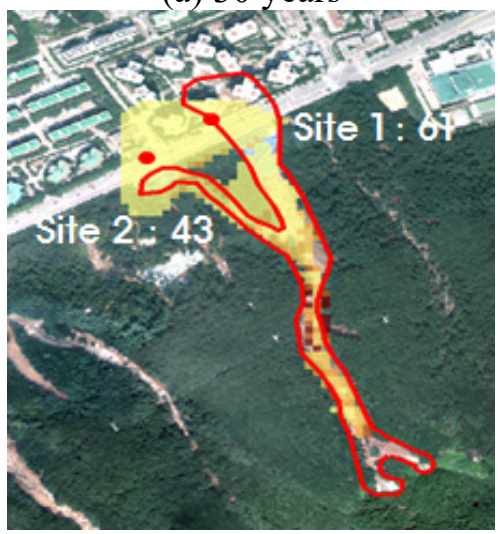

(c) 100 years

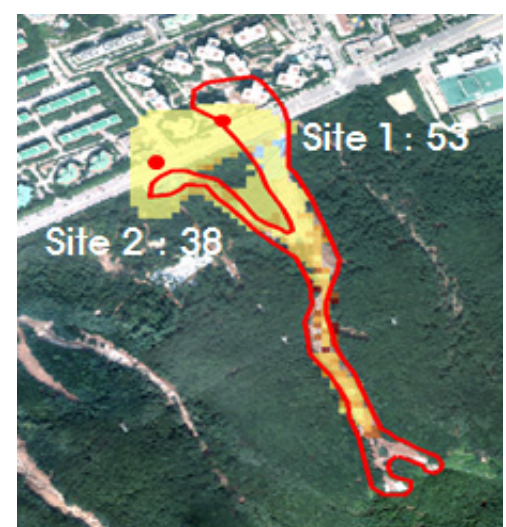

(b) 50 years

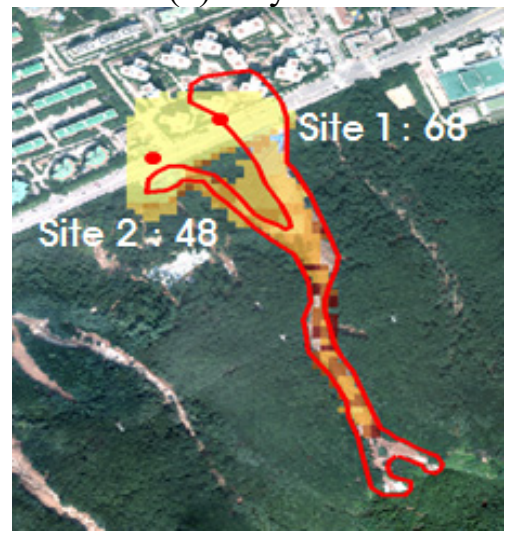

(d) 200 years

Figure 5: Impact force of Seoul (RAMMS, unit=Kpa).

\subsection{Comparison of impact force between RAMMS model and Flo-2D model}

Impact forces were analyzed for two sites, Site 1 and Site 2, which have real buildings in Chuncheon and Seoul. The comparison of the two models showed a similar tendency, but the impact force of the Flo-2D model was somewhat higher than that of the RAMMS model. The impact comparison results are shown in Tables 4 and 5. 


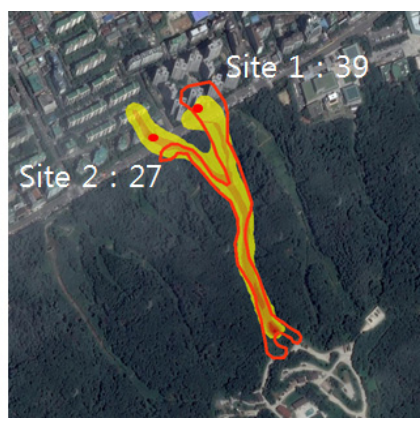

(a) 30 years

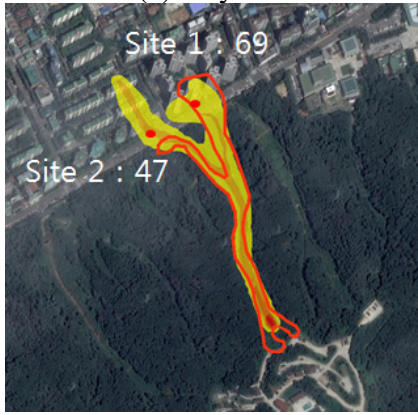

(c) 100 years

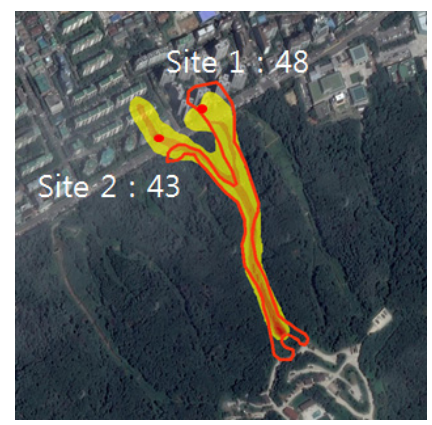

(b) 50 years

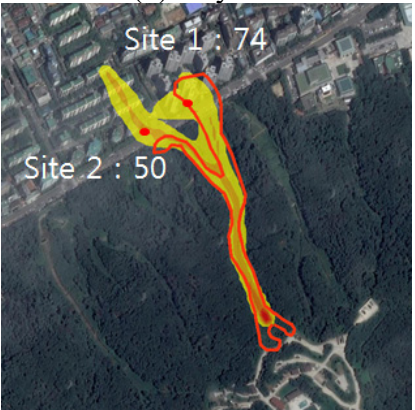

(d) 200 years

Figure 6: Impact force of Seoul (Flo-2D, unit=Kpa).

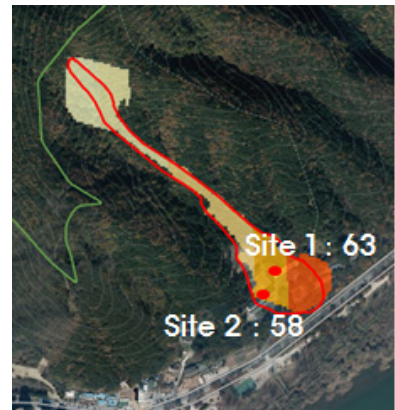

(a) 30 years

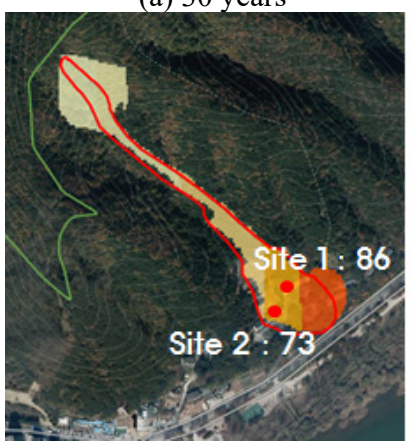

(c) 100 years

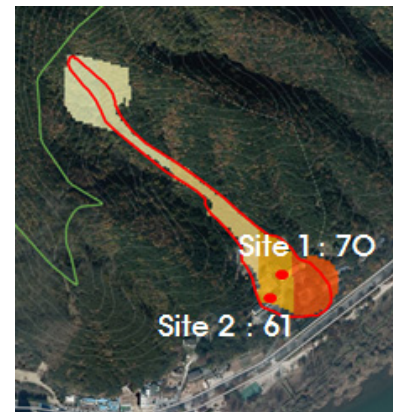

(b) 50 years

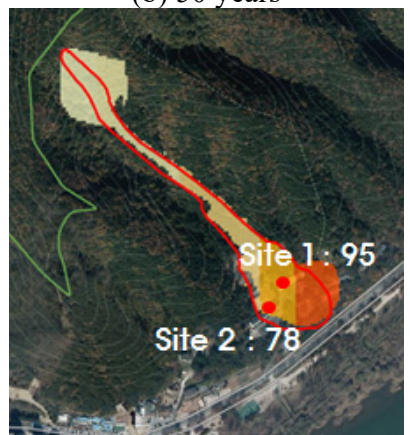

(d) 200 years

Figure 7: Impact force of Chuncheon (RAMMS, unit=Kpa). 


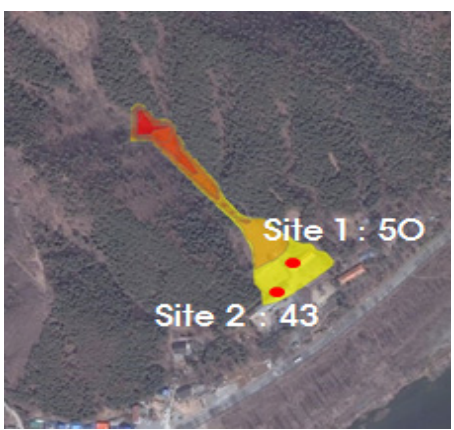

(a) 30 years

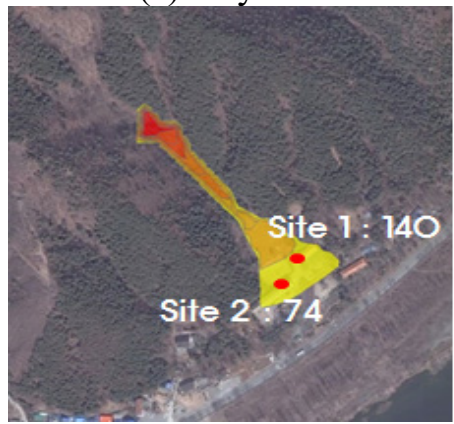

(c) 100 years

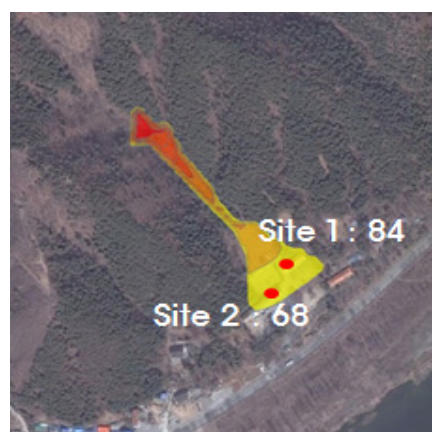

(b) 50 years

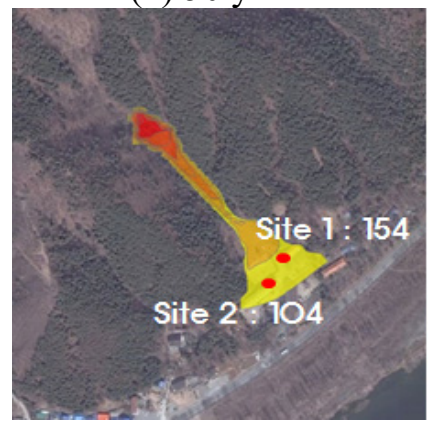

(d) 200 years

Figure 8: Impact force of Chuncheon (Flo-2D, unit=Kpa).

Table 4: Model application result data(Seoul).

\begin{tabular}{|c|c|c|c|c|c|c|}
\hline \multirow{2}{*}{} & \multicolumn{2}{|c|}{ Area $\left(\mathrm{m}^{2}\right)$} & \multicolumn{2}{c|}{ Flow Height $(\mathrm{m})$} & \multicolumn{2}{c|}{ Velocity $(\mathrm{m} / \mathrm{s})$} \\
\cline { 2 - 7 } & RAMMS & Flo-2D & RAMMS & Flo-2D & RAMMS & Flo-2D \\
\hline 30 years & 71,190 & 64,100 & 0.821 & 0.103 & 7.919 & 1.805 \\
\hline 50 years & 72,016 & 65,290 & 1.512 & 1.042 & 8.132 & 3.083 \\
\hline 100 years & 73,651 & 68,900 & 2.063 & 2.113 & 8.373 & 5.692 \\
\hline 200 years & 75,247 & 70,100 & 3.152 & 4.227 & 8.641 & 6.834 \\
\hline
\end{tabular}

Table 5: Model application result data(Chuncheon).

\begin{tabular}{|c|c|c|c|c|c|c|}
\hline \multirow{2}{*}{} & \multicolumn{2}{|c|}{ Area $\left(\mathrm{m}^{2}\right)$} & \multicolumn{2}{c|}{ Flow Height $(\mathrm{m})$} & \multicolumn{2}{c|}{ Velocity(m/s) } \\
\cline { 2 - 7 } & RAMMS & Flo-2D & RAMMS & Flo-2D & RAMMS & Flo-2D \\
\hline 30 years & 43,213 & 41,920 & 0.671 & 0.492 & 5.124 & 2.113 \\
\hline 50 years & 44,204 & 42,523 & 1.542 & 1.004 & 5.941 & 3.358 \\
\hline 100 years & 45,925 & 44,224 & 2.013 & 1.925 & 6.843 & 4.122 \\
\hline 200 years & 47,747 & 46,650 & 2.944 & 2.784 & 7.216 & 5.352 \\
\hline
\end{tabular}




\section{CONCLUSION}

The study focused on Seoul and Chuncheon as target areas for analysis, which both experienced damage from a debris flow in 2011. Two-dimensional debris flow numerical analysis models, RAMMS and Flo-2D, were applied to compare the impact forces. Using the rainfall data from the past 55 years for Seoul and Chuncheon, the GEV (extreme value) probability of rainfall was calculated and the time distribution of rainfall was performed by using the Huff third quartile. A distributed rainfall-runoff model, S-RAT, was used to estimate the runoff, total runoff, and peak flood to be applied to the models, RAMMS and Flo-2D. The RAMMS model and the Flo-2D model were calibrated using the rainfall index from July 2016 and the NSI quantitative and the parameters were corrected to the nearest damage range in the Seoul and Chuncheon areas. Rainfall levels (measured in frequencies of 30 years, 50 years, 100 years and 200 years) were applied to compare impact force.

As a result of applying the calibrated parameters to the model, the RAMMS model and Flo-2D model showed error rates of 5.7\% and 3.1\% in Seoul, and 5\% and 5.2\% in Chuncheon. The result of the comparison between the two models, Flo-2D and RAMMS, is as follows: regarding the comparison between error rate and the actual extent of the damage, RAMMS has an error rate of $3 \%$ for a 30 -year frequency, $4 \%$ for 50 years, $6 \%$ for 100 years, and $8 \%$ for a 200 years frequency in Seoul. The closest level was the area with a 30-year frequency. On the other hand, Flo-2D showed an error rate of $8 \%$ for a 30 -year frequency, $6 \%$ for 50 years, $0.009 \%$ for 100 years, and $1 \%$ for a 200 -year frequency. The closest level was the area of 100-year frequency. Both Chuncheon and Seoul showed a matching tendency to some extent; however, Chuncheon's results showed vast differences between the 100-year frequency and the 200-year frequency. Additional analysis is required to identify the cause of the difference. In addition, calculating impact forces for different facility materials will contribute to the selection of materials by facility spot.

\section{ACKNOWLEDGEMENT}

This research was supported by a grant [2017-MPSS31-004] from the Supporting Technology Development Program for Disaster Management funded by Korean Ministry of Public Safety and Security (MPSS).

\section{REFERENCES}

[1] Nam, D.H., Lee, S.H., Jun, K.W. \& Kim, B.S., A Study on the Debris Flow Movement and the Run-out Calculation Using the Coupling of Flood Runoff Model and Debris Flow Model. Crisisonomy, 12(8), pp. 131-143, 2016.

[2] Kim, B.S., Yoon, S.K., Yang, D.M. \& Kwon, H.H., Development of Grid-Based Conceptual Hydrologic Model. Journal of Korea Water Resources Association, 43(7), pp. 667-679, 2010.

[3] Tak, W.J., A Study on the Transport and Diffusion Range Estimate of Debris Flow Using RAMMS, Kangwon National University, 2015.

[4] Kang, H.S. \& Kim, Y.T., Study on Physical Vulnerability Curves of Buildings by Numerical Simulation of Debris Flow. J. Korean Soc. Hazard Mitig., 15(5), pp. 155167, 2015. 